\title{
ANALISIS JANUARY EFFECT TERHADAP RETURN PASAR INDEKS LQ-45 PERIODE 2016-2018
}

\author{
Dani Prabowo \\ Jurusan Manajemen \\ Universitas Pembangunan Nasional "Veteran" Yogyakarta \\ e-mail : danyprabowo19@gmail.com \\ Sudarman \\ Staf Pengajar Jurusan Manajemen \\ Universitas Pembangunan Nasional "Veteran" Yogyakarta \\ e-mail : sudarman_upn@yahoo.co.id \\ Agung Satmoko \\ Staf Pengajar Jurusan Manajemen \\ Universitas Pembangunan Nasional "Veteran" Yogyakarta \\ e-mail : agungsatmoko@yahoo.co.id
}

\begin{abstract}
The purpose of this study is prove the existence of January effect anomaly on the market return of the LQ-45 Index for the period 2016-2018. The variable in this study is the market return of the LQ-45 index stock group. This study uses descriptive analysis and statistical analysis, namely different tests of two independent averages. The result of the study show that there is no difference in the average return in January with other months (FebruaryDecember), so there is no phenomenon of the January effect on the LQ-45 Index during the period 2016-2018.
\end{abstract}

\begin{abstract}
ABSTRAK
Tujuan dari penelitian ini adalah membuktikan adanya anomali January effect terhadap return pasar Indeks LQ-45 periode 2016-2018. Variabel dalam penelitian ini adalah return pasar kelompok saham indeks LQ-45. Penelitian ini menggunakan analisis deskriptif dan analisis statistik yaitu uji beda dua rata-rata independen. Hasil penelitian menunjukkan bahwa tidak ada perbedaan rata-rata return bulan Januari dengan bulan lainnya (Februari-Desember), sehingga tidak ada fenomena pengaruh Januari terhadap Indeks LQ-45 selama periode 20162018.
\end{abstract}

Kata Kunci: Efek Januari, Pasar Kembali, Pengembalian Rata-rata

\section{PENDAHULUAN}

Pasar modal menjadi salah satu indikator dalam penilaian perekonomian suatu negara. Kegiatan-kegiatan di pasar modal dapat membentuk suatu perekonomian menjadi lebih baik maupun sebaliknya. Untuk itu pasar modal harus menujukkan pergerakan yang baik. Pasar modal yang baik adalah pasar modal yang efisien, dimana pasar memiliki sekuritas yang harganya mencerminkan informasi yang ada. Fama (1970) memperjelas konsep pasar efisien dengan membaginya dalam tige bentuk yaitu Weak form, Semi strong, Strong form efficiency. Pasar modal yang efisien memiliki ciri pola pergerakan yang acak atau disebut sebagai pola random walk. Harga saham bergerak secara acak bergantung atas 


\section{Buletin Ekonomi}

informasi yang datang sehingga tidak bisa diprediksi, untuk itu investor perlu cepat dalam menerima dan menganalisis informasi.

Penelitian mengenai reaksi pasar modal terhadap suatu informasi yang datang sudah banyak dilakukan diberbagai negara. Namun, dari penelitian tersebut justru ditemukan hal yang menyimpang dari konsep pasar efisien yang disebut sebagai gangguan atau anomali. Secara umum ada beberapa bentuk anomali yang terdapat dalam pasar modal salah satunya adalah January Effect. January Effect adalah anomali musiman dimana menampilkan return bulan Januari lebih tinggi dibanding bulan-bulan lainnya. Penelitian mengenai January effect sudah banyak dilakukan diberbagai negara Gharaibeh (2017) yang meneliti di 4 Indeks Arab menjelaskan bahwa return di bulan Januari di indeks pasar Yordania dan Maroko lebih tinggi, untuk pasar Mesir dan Lebanon juga memberikan return yang berbeda tetapi tidak terlalu tinggi. Hasil yang berbeda didapatkan oleh Ahmad dan Ahmed (2014) yang tidak menemukan ada perubahan return pada bulan Januari di Bursa Saham Karachi (KSE).

Penelitian mengenai January effect di indonesia juga mendapatkan hasil yang beragam. Andriani (2018) menemukan bahwa terdapat perbedaan return saham pada bulan Januari dengan bulan lainnya pada perusahaan BUMN yang terdaftar di Bursa Efek Indonesia. Hasil serupa juga didapatkan oleh Fitriyani dan Sari (2013) yang menemukan bahwa terdapat perbedaan return saham dan abnormal return pada kelompok saham Indeks LQ-45 di tahun penelitiannya dan penelitian yang dilakukan oleh Yoga (2010) yang menemukan bahwa terdapat January effect disalah satu sektor yaitu sektor konsumsi.

Berbeda dengan penelitian diatas, Sari dan Sisdyani (2014) tidak menemukan perbedaan rata-rata return bulan Januari dengan bulan-bulan lainnya sehingga tidak terjadi January effect di pasar modal Indobesia. Sama seperti penelitian yang dilakukan oleh Kadir dan Kewal (2014) yang tidak menemukan January effect di perusahan Indeks LQ-45. Berdasarkan latar belakang diatas, maka peneliti akan menganalisis keberadaan fenomena January effect pada indeks LQ-45 pada periode tahun 2016-2018.

1. Investasi

investasi adalah komitmen atas sejumlah dana atau sumber daya lainnya yang dilakukan pada saat ini, dengan tujuan memperoleh sejumlah keuntungan di masa mendatang (Tandellin, 2010). Menurut Jones (1999) definisi investasi adalah "An investment can be defined as the commitment of funds to one or more assets that will be held over some future time period." Artinya investasi dapat didefinisikan sebagai komitmen untuk menunda satu aset atau lebih, yang dilakukan selama beberapa periode mendatang.

2. Pasar Modal

Menurut Undang-Undang Pasar Modal Nomor 5 Tahun 1995, pasar modal didefinisikan sebagai kegiatan yang bersangkutan dengan penawaran umum dan perdagangan efek, perusahaan publik yang berkaitan dengan efek yang diterbitkannya, serta lembaga dan profesi yang berkaitan dengan efek. Dengan demikian pasar modal dapat diartikan sebagai tempat bertemunya pembeli dalam hal ini disebut sebagai investor sebagai pihak yang memiliki kelebihan dana dengan perusahaan sebagai pihak yang memerlukan dana dengan cara memperjual belikan sekuritas.

3. Pasar Modal Efisien

Konsep pasar modal efisien adalah pasar dimana harga semua sekuritas yang diperdagangkan telah mencerminkan semua informasi yang tersedia. Dalam hal ini, informasi bisa meliputi semua informasi yang tersedia baik informasi di masa lalu, maupun informasi saat ini, dan informasi yang bersifat sebagai pendapat atau opini rasional yang beredar di pasar yang dapat mempengaruhi perubahan harga (Tandelilin, 2010). Fama (1991) dalam Tandellin (2010), mengklasifikasikan bentuk pasar yang efisien kedalam tiga efficient market hypothesis (EMH), sebagai berikut: 


\section{Buletin Ekonomi}

a. Efisien dalam bentuk lemah (weak form efficiency).

b. Efisien dalam bentuk setengah kuat (Semi strong efficiency).

c. Efisien dalam bentuk kuat (Strong foam efficiency).

4. Saham

Saham merupakan bukti kepemilikan atas aset-aset perusahaan perusahaan yng menerbitkan saham. Dengan memiliki saham suatu perusahaan, maka investor akan mempunyai hak terhadap perndapatan dan kekayaan perusahaan, setelah dikurangi dengan pembayaran semua kewajiban perusahaan (Tandellin, 2010). Saham dibedakan menjadi dua jenis :

a. Saham biasa, yaitu sertifikat yang menunjukkan bukti kepemilikan suatu perusahaan. Pemegang saham bisa memiliki hak suara proposional pada berbagai keputusan dalam rapat umum pemegang saham (RUPS).

b. Saham preferen, yaitu Saham preferen merupakan saham yang memiliki sifat gabungan antara obligasi dan saham biasa. Saham preferen dapat memberikan hasil yang tetap berupa deviden.

5. Return Saham

Menurut (Jogiyanto, 2010) return merupakan hasil yang diperoleh dari investasi. Return dapat berupa keuntungan realisasi yang sudah terjadi (realized return) atau keuntungan ekspektasi yang belum terjadi tetapi yang diharapkan akan terjadi dimasa mendatang (expected return).

6. Anomali Pasar

Anomali merupakan bentuk penyimpangan yang terjadi di pasar modal. Penyimpangan yang terjadi di pasar modal menyebabkan pasar sulit untuk diprediksi. Jones (2014) menyatakan bahwa "market anomalies is techniques or strategies that appear to be contary to an efficient market." Dengan kata lain, berarti bahwa anomali pasar adalah teknik-teknik atau strategi-strategi yang berlawanan dengan konsep pasar efisien. Banyak investor yang memanfaatkan adanya kemungkinn terjadinya anomali pasar ini untuk mendapatkan keuntungan yang tidak normal (abnormal return).

Levy (dalam Gumanti, 2011) menjelaskan keempat anomali tersebut sebagai berikut:

a. Anomali perusahaan (Firm anomalies).

b. Anomali musiman (Seasonal anomalies).

c. Anomali Peristiwa (Event anomalies).

d. Anomali Akuntansi (Accounting anomalies).

7. January Effect

Menurut Darmadji (2001), January effect merupakan istilah yang dimaksudkan untuk menggambarkan bahwa pada bulan Januari setiap tahun, umumnya menunjukkan tingkat pengembalian yang tinggi dibandingkan bulan-bulan lainnya.

Menurut Sharpe (1995) ada beberapa penyebab terjadinya anomali perilaku saham pada bulan Januari, yaitu:

a. Tax loss selling, yaitu suatu fenomena dengan menjual harga saham-saham yang hasilnya buruk dengan tujuan untuk memperbaiki laporan keuangannya yang nantinya akan berdampak pada pengurangan pajak pada akhir tahun.

b. Window dressing, yaitu tindakan atau strategi mempercantik laporan keuangan perusahaan sebelum ditampilkan kepada para pemegang saham. Tujuannya adalah untuk menarik para investor untuk membeli saham mereka sehingga menaikkan harga saham di awal tahun.

c. Small stock's beta, yaitu saham dengan kapitalisasi pasar kecil memiliki resiko yang lebih besar pada bulan Januari daripada bulan lainnya, namun dapat memberikan return yang lebih besar. 
Kerangka Konseptual

Perbedaan

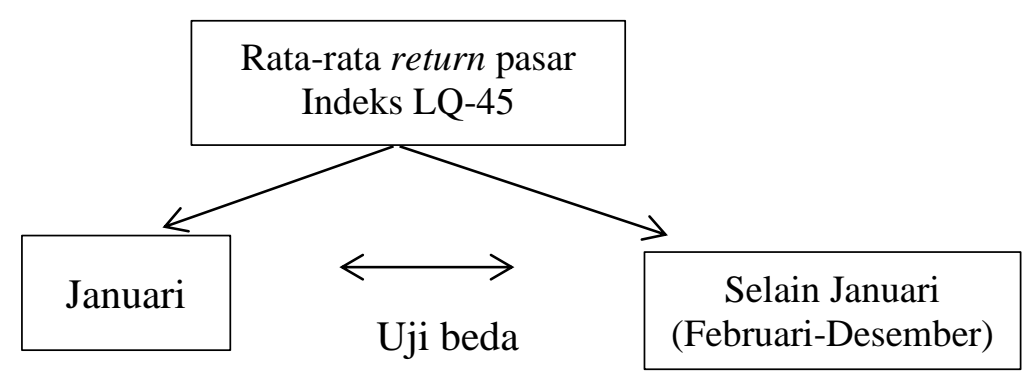

\section{METODE}

Jenis penelitian ini adalah penelitian kuantitatif. Objek dalam penelitian ini adalah indeks LQ-45 dengan periode pengamatan selama 3 tahun pada tahun 2016-2018. Data dalam penelitian ini didapatkan dari website resmi Yahoo finance. Variabel dalam penelitian ini adalah return pasar.

\section{ANALISIS DAN PEMBAHASAN}

Berdasarkan gambar 1 diatas dapat dilihat bahwa rata-rata return Januari selama periode pengamatan tidak menujukkan return yang paling tinggi dibandingkan dengan bulan-bulan lainnya. Return tertinggi terjadi pada bulan Desember di tahun 2017 sebesar 0,45\%. Hal tersebut dikarenakan lembaga pemeringkat internasional Fitch Ratings menaikkan peringkat utang indonesia dari BBB- menjadi BBB dengan outlok stabil, sehingga pasar diwarnai sentimen positif dan bergerak menguat di bulan Desember. Secara keseluruhan return tetinggi terjadi pada bulan Desember. Kenaikan return yang tinggi dibulan Desember disebabkan oleh berbagai faktor, salah satunya adalah aksi window dressing atau mempercantik laporan keuangan yang dilakukan oleh emiten-emiten yang akan dipublikasikan di akhir tahun. Terdapat beberapa faktor tidak terjadinya January effect di pasar modal Indonesia, berkaitan dengan tax loss selling yang menjual saham-saham yang dimiliki guna mengurangi pajak tahunan di akhir tahun, di Indonesia pembayaran pajak bukan di akhir tahun tetapi di bulan Maret. Selain itu, menurut Sari dan Sisdyani (2014) dalam penelitiannya mengatakan bahwa teterdapat perbedaan budaya antara Indonesia dengan negara-negara maju lainnya, dimana pada negara maju pada akhir tahun atau pada bulan Desember terdapat beberapa perayaan besar yaitu natal dan tahun baru. Pada bulan tersebut mayoritas penduduk merayakan hari tersebut secara besar-besaran sehingga dibutuhkan dana yang banyak. Investor cenderung menahan investasinya guna mencukupi kebutuhan tersebut atau bahkan menjual saham yang dimilikinya. Sedangkan di Indonesia mayoritas penduduk adalah muslim dimana event yang paling besar perayaannya adalah hari raya Idul Fitri, sehingga perilaku investornya berbeda dengan negara maju yang cenderung menahan investasinya guna mencukupi kebutuhan mereka pada perayaan natal dan tahun baru dan melakukan pembelian dan penyusunan strategi investasi baru sehingga menaikkan return di awal tahun. 


\section{Buletin Ekonomi}

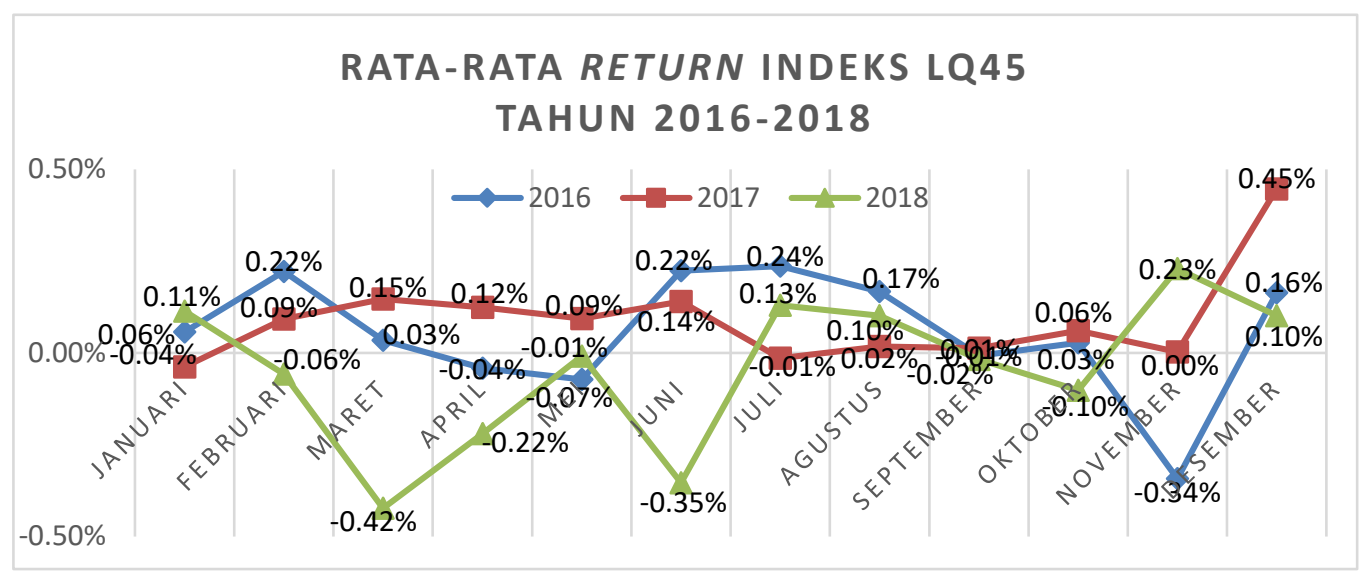

GAMBAR 1

GRAFIK RATA-RATA RETURN INDELS LQ-45 TAHUN

\section{KESIMPULAN DAN SARAN}

Penelitian tentang January effect pada Indeks LQ-45 yang bertujuan untuk mengetahui adanya perbedaan rata-rata return pasar bulan Januari dengan bulan selain Januari (Februari-Desember) dapat disimpulkan bahwa tidak terdapat perbedaan rata-rata return pasar bulan Januari dengan bulan selain Januari (Februari-Desember) di indeks LQ-45 selama periode tahun 2016-2018 sehingga tidak terjadi fenomena January effect di indeks LQ-45.

Berdasarkan kesimpulan diatas, saya menyarankan kepada peneliti Selanjutnya:

1. Untuk melakukan pengujian pada kelompok indeks yang berbeda seperti Kompas100, IDX30, Indeks Saham Syariah Indonesia (ISSI), maupun Indeks Sektoral dan indeks lainnya. Hal ini dimaksudkan agar menjadi pembanding dari hasil penelitian ini.

2. Karena dalam penelitian ini justru ditemukannya return bulan Desember yang lebih tinggi maka saya menyarankan agar meneliti lebih mendalam mengenai fenomena tersebut.

\section{DAFTAR PUSTAKA}

Ahmad, Tauseef, and Ahmed Syed N., 2014, The January Effect on Stock Market,European Academic Research,1(11): 3817-3825.

Andriani, Agung Mas,2018, Analisis January Effect Pada Perusahaan BUMN di Bursa Efek Indonesia, Majalah Ilmian Untab, Vol. 15, No.1.

As'adah, Luluk, 2009, Pengaruh January Effect terhadap Abnormal Return dan Volume Perdagangan pada Saham di Jakarta Islamic Index (JII), Skripsi, Jurusan Mu'amalah pada Fakultas Syari'ah Universitas Islam Negeri Sunan Kalijaga Yogyakarta.

Awat, Napa J., 1999, Manajemen Keuangan Pendekatan Matematis, Edisi Pertama, Jakarta : PT Gramedia Pustaka Utama. 


\section{Buletin Ekonomi}

Darmadji, dan H. Fakhrudin M., 2006, Pasar Modal di Indonesia pendekatan

Tanya Jawab, Jakarta: Salemba empat.

Fitiyani, Indah, dan Maria M. Ratna Sari, Analisis January Effect Pada Kelompok Saham Indeks LQ45 tahun 2009-2013, E-Jurnal Akuntansi Universitas Udayana, 4(2):421-438.

Gharaibeh, Omar, 2017, The January Effect: Evidence From Four Arabic Market Indices, International Journal of Academic Research in Accounting, Finance and Management Sciences, 7(1): 144-150.

Gumanti, Tatang Ary, 2011, Manajemen Investasi: Konsep, Teori, dan Aplikasi, Jakarta: Mitra Wacana Media.

Husnan, Suad. 2003, Dasar-Dasar Teori Portofolio dan Analisis Sekuritas. Yogyakarta: UPP AMP YKPN.

Jogiyanto, H.M., 2010, Teori Portofolio dan Analisis Investasi, Edisi Ketujuh, Yogyakarta: BPPE.

Jones, Charles P., 2014, Investment Principles and Concept, Twelfth Edition, Singapura: John Wiley and Sons.

Kadir, Sherly, dan Suramaya Suci K., 2014, Fenomena January Effect di Pasar Modal Indonesia, Jurnal Keuangan dan Bisnis, Vol.12, No.1.

Sari, Fitri Aprilia, dan Eka Ardhani Sisdyani, 2014, Analisis January Effect Di Pasar Modal Indonesia, E-Jurnal Akuntansi Universitas Udayana.

Sekaran, Uma, 2006, Research Methods For Bussines, Jakarta: Salemba Empat.

Sharpe, William F., Alexander Gordon J., dan Bailey V., 1995, Investment, New York:Prantice Hall

Sugiyono, 2013, Metode Penelitian Manajemen, Bandung: Alfabeta,

Sunariyah, 2004, Pengantar Pengetahuan Pasar Modal, Edisi Keempat, Yogyakarta: UPP AMP YKPN.

Tandellin, Enduardus, 2010, Portofolio dan Investasi, Yogyakarta: Percetakan Kanisius.

Yoga, 2010, Analisis Fenomena January Effect terhadap Return Pasar di Bursa Efek Indonesia, E-Jurnal STIE Atma Bhakti Surakarta, 1(2): 1-1 